\title{
Diphtheria: Clinical Manifestations, Diagnosis, and Role of ImmunizationIn Prevention
}

\author{
MurtazaMustafa $^{1}$, IM.Yusof ${ }^{2}$, MS, Jeffree ${ }^{3}$, EM.Illzam ${ }^{4}$, SS.Husain ${ }^{5}$, \\ AM.Sharifa ${ }^{6}$. \\ 1,2,3,5, Faculty of Medicine and Health Sciences, University malaysia, Sabah, Kota Kinabalu, \\ Sabah, Malaysia. \\ ${ }^{4}$ Clinic Family Planning Association, Kotakinabalu, Sabah, Malaysia \\ ${ }^{6}$ Quality Unit Hospital Queen Elizabeth, Kota Kinabalu, Sabah, Malaysia
}

\begin{abstract}
Diphtheria outbreaks, though very rare, still occur worldwide, in the developed and developing countries. Diphtheria has high mortality in non-vaccinated populations. Corynebacterium diphtheria produce very potent toxin when infected with a bacteriophage that migrates the toxin-encoding genetic elements into bacteria. The $R$ domain binds to a cell surface receptor, permitting the toxin to enter the cell by receptor mediated endocytosis.The toxin elaborated locally induces a dense necrotic coagulum composed of fibrin,leukocytosis, dead respiratory epithelial cells, leading to white-gray brown pseudomembrane., a common cause of death is suffocation after aspiration of membrane. Complications may include myocarditis, inflammation of nerves, kidney problems, and bleeding due to low blood platelets, Diagnosis by isolation of Corynebacterium diphtheria from gram stain or throat culture, or histopathogic diagnosis. Treatment with metronidazole, erythromycin, procaine penicillin $G$ orally or by injection or rifampin or clindamycin for patients with allergies to penicillin or erythromycin.Prevention by immunization, diphtheria vaccine is on the World Health Organization list of essential medicines, most important needed in the basic health system. Recommendations from the Advisory Committee on Immunization Practices, 2006-2008, published by CDC are useful.Anti-vaccination groups are doing more harm than good to the society.
\end{abstract}

Keywords:Diphtheria,Pseudomembrane.Clinicalmanifestations,Immunization.

\section{Introduction.}

Diphtheria from Greek word diphtheria meaning leather, is an infection caused by the bacterium Corynebacterium diphtheriae [1].The disease was first described in the $5^{\text {th }}$ century BC by Hippocrates. The bacterium was discovered in 1882 by Edwin Kleb[1].In 2013,4,700 cases were officially reported down from nearly 100,000 in 1980[2].It is believed ,however, that about a million cases occurred per year before 1980s[2].It currently occurs most often in Sub-Sharan Africa,India, and Indonesia[2,3].In June 2016,three cases of diphtheria were reported in Malaysia with one death[4].In 2013, it resulted in 3,300 deaths down from 8,000 deaths in 1990[5].In areas where it is still common, children are most affected. It is rare in the developed world due to widespread vaccination [2].In the United States 57 cases were reported between 1990 and 2004.Death occurs in between 5\% and 10\% those affected[1].Outbreaks, though very rare, still occur worldwide, including in developed nations, such as Germany among non-vaccinated children. Clinicalmanifestations may vary from mild to severe. They start 2 to 5 days after exposure[2].Clinical symptoms often come on fairly gradually beginning with sore throat and fever[2].In severe cases a grey or white patch develops in the throat[1,2].Complications may include myocarditis, inflammation of nerves, kidney problems, and bleeding due to low blood platelets[1].Treatment is with antibiotic erythromycin or penicillin G,tracheostomy may be needed in severe cases[1].Prevention is by diphtheria toxoid, four doses, given with tetanus toxoid and acellular pertussis vaccine, are recommended during childhood.[1].Adults should receive only one booster, and travelers may benefit from a booster at a 5-year interval.[6,].The paper reviews the current literature, clinical manifestations, and role of vaccination in prevention of diphtheria.

\section{History and Discovery of Diphtheria}

Diphtheria is an ancient disease described in the $5^{\text {th }}$ century by Hippocrates $\{1\}$.In Spain experienced an outbreak of diphtheria. The year known as "EL Ano de losGarrotilos"-the year of Strangulations, in history of Spain [7].During the years 1735 to 1740,New England and Middle Atlantic states were ravaged by a "throat distemper" which from its description was almost certainly diphtheria, and may have caused the death of more than $20 \%$ of the entire population under 15 years of age[8].In 1735, diphtheria epidemic swept through New England [9].In 1856,Victor Fourgeaud described an epidemic of diphtheria in California[10].In 1883 Edwin 
Klebs identified the bacterium,and in 1884 Loeffler isolated the bacterium. Bacterium was named as KlebsLoeffler bacterium [11,12].Currently bacterium is known as Corynebacterium diphtheriae.

Joseph P0'Dwyer introduced the 0'Dwyer tube for laryngeal intubation in patients with obstructed larynx in 1885.It soon replaced tracheostomy as the emergency diphtheria intubation method[13].In 1888,Emile Roux and Alexandre Yersin showed that a substance produced by C.diphtheriae caused symptoms of diphtheria in animals[14].In 1890.Shibasburo Kitasatto and Emil von Behring immunized guinea pigs with heat-treated diphtheria toxin.The first cure of a person with diphtheria. On Behring won first Nobel Prize in medicine in 1901 for his work on diphtheria[15,16]In 1895,HK Mulford Company of Philadelphia started production and testing of diphtheria in the United States[17].

In 1905,Franklin Royer published a paper urging timely treatment for diphtheria and adequate doses of antitoxin[18].Bela Schick developed Schick test to detect preexistent immunity to diphtheria in an exposed person. A diphtheria vaccine was developed, and deaths began declining in 1924[19].In 19919, in Dallas,Texas,USA, 10 children were killed and 60 others made seriously ill by toxic antitoxin which had passed the tests of the NY State Health Department.Mulford Company(manufacturers) paid damages in every case[20].In 1920s, there were an estimated 100,000 to 200,00 cases of diphtheria per year in the United States, causing 13,000 to 15,000 deaths per year[17].In 1926,Alexander Thomas Glenny increased the effectiveness of diphtheria toxoid by treating it with aluminum salts[21].

In 1974,WHO included DPT(diphtheria,pertussis,and tetanus) vaccine in their expanded program on immunization for developing countries. In 1975, an outbreak of cutaneous diphtheria in Seattle, Washington was reported [22].In 1994,the Russian Federation saw 39,703 diphtheria cases. In contrast in 1990 there had been only 1,211 cases [23].In 2010,a case of diphtheria was diagnosed in Port-au-Prince,Haiti after devastating 2010 Haiti earthquake. The 15-year old male patient died while workers searched for antitoxin[24].In 2013,three children died of diphtheria in Hyderabad India[25].In 2015, a case of diphtheria was diagnosed in Barcelona ,Spain.The 6 years child who died of illness had not been vaccinated due to parental opposition to vaccination[26].In 2016, a 3 years old girl died of diphtheria in the University Hospital of Antwerp,Belgium[27].In June,July,2016,there were 22 diphtheria cases with 5 died of diphtheria in Malaysia [28].

\section{Diphtheria Toxin}

Diphtheria toxin was discovered in 1890 by EA Von Behring. In 1951,Freeman found that the toxin gene was not encoded on the bacterial chromosome, but by a lysogenic phage infecting all toxigenic strains[2931].Diphtheria toxin is an exotoxin secreted by Corynebacterium diphtheria, the pathogenic bacteria that cause diphtheria[32].The toxin causes the disease diphtheria in humans by gaining entry into the cell cytoplasm and inhibiting protein synthesis[33].

\section{Toxin Structure}

Diphtheria toxin is a single polypeptide chain of 535 amino acids consisting of two subunits linked by disulfide bridges, known as an A-B toxin. Binding to cell surface of B subunit (the less stable of two subunits)allows the A subunit(the more stable part of the protein) to penetrate the host cell[34].The crystal structure of the diphtheria toxin homodimer has been determined to 2.5 Angstrom resolution. The structure reveals a Y-shaped molecules consisting of three domains. Fragment $\mathrm{A}$ contains the catalytic $\mathrm{C}$ domain, and fragment $\mathrm{B}$ consists of the $\mathrm{T}$ and $\mathrm{R}$ domains [35].

The amino-terminal catalytic domain, known as the $\mathrm{C}$ domain, has an unusual beta+alphafold[36].The $\mathrm{C}$ domain blocks protein synthesis by transfer of ADP-ribose from NAD to a diphthamide residue of eukaryotic elongation factor 3(eEF-2)[37].A central translocation domain, known as the T domain or TM domain, has a multi-helical globin fold with two additional helices at the amino terminus but no counterpart to the first globin helix. This domain is thought to unfold in the membrane[38].A pH-induced conformational change in the $\mathrm{T}$ domain triggers insertion into the endosomal membrane and facilitates the transfer of the $\mathrm{C}$ domain into cytoplasm[36].The carboxyl-terminal receptor-binding domain, known as the $\mathrm{R}$ domain, has a beta-sandwich fold consisting of nine strands in two sheets with Greek-key topology, it is a subclass of immunoglobulin-like fold[36,rpt].The R domain binds to a cell surface receptor, permitting the toxin to enter the cell by receptormediated endocytosis[37].

\section{Mode of Action}

Diphtheria toxin is produced by Corynebacterium diphtheria only when infected with a bacteriophage that migrates the toxin-encoding genetic elements into bacteria [39, 40].Diphtheria toxin is a single 60kDa molecular weight protein composed of two peptide chains, fragment A and fragment $\mathrm{B}$, held together by a disulfide bond. Fragment $\mathrm{B}$ is a recognition subunit that gains the toxin entry into host cell by binding to the EGF-like domain of heparin -binding EGF-like growth factor (HB-EGF) on the cell surface. This signals the 
cell to internalize the toxin within an endosome via receptor-mediated endocytosis. Inside the endosome.Inside the endosome, the toxin is split by trypsin-like protease into its individual A and B fragments. The acidity of the endosome causes fragment $\mathrm{B}$ to create pores in the endosome membrane, herby catalyzing the release of fragment A into the cell's cytoplasm.

A fragment A inhibits the synthesis of new proteins in the affected cell.It does this by catalyzing ADPribosylation of elongation factor EF-2- a protein that is essential to the translation step to protein synthesis. This ADP-ribosylation involves the transfer of an ADP-ribosome from NAD+ to a diphthamide(a modified histidine) residue within the EF-2 protein. Since EF-2 is needed for the moving of tRNA from the A site to $\mathrm{P}$-site of the ribosome during protein translation.ADP-ribosylation of EF-2 prevents protein synthesis.ADP-ribosylation of EF-2 is reversed by giving high doses of nicotinamide (a form of vitamin $\mathrm{B}_{3}$ ), since this is one of the reaction's end-products, and high amounts will drive the reaction in the opposite direction[37,38].

\section{Pathogenesis}

C.diphtheriae is not a very invasive organism, ordinarily remaining in the superficial layers of the respiratory mucosa and skin lesions, where it can induce a mild inflammatory reaction in the local tissue. The major virulence of C.diphtheriae results from the action of its potent exotoxin, which inhibits protein synthesis in mammalian cells but not in bacteria [41]. The 62,000-dalton polypeptide toxin is composed of two segments: $\mathrm{B}$, which binds to specific receptors on susceptible cells, and A, the active segment. After proteolytic cleavage of the bound molecule, segment A, enters the cell, where it catalyzes inactivation of the transfer RNA(tRNA) translocase "elongation factor 2 ",present in the eukaryotic cells but not in bacteria. Loss of this enzyme prevents the interaction of messenger RNA and tRNA stopping further addition of amino acids to developing polypeptide chains[42]. The toxin effects all cells in the body, but most prominent effects are on heart (myocarditis), nerves(demyelination), and kidneys(tubular necrosis).Diphtheria toxin is extremely potent: a single molecule can stop protein synthesis in a cell within hours, and $0.1 \mu \mathrm{g} / \mathrm{kg}$ will kill susceptible animals[41].

Within the first few days of respiratory tract infection, toxin, elaborated locally induces a dense necrotic coagulum composed of fibrin, leukocytes, erythrocytes, dead respiratory epithelial cells, and organisms. Removal of this adherent gray-brown"pseudomembrane" reveals a bleeding edematous submucosa. The membrane nan be local (tonsillar,pharyngeal,nasal) or extend widely, forming a cast of the pharynx and tracheobronchial tree. The underlying soft tissue edema and cervical adenitis can be intense, and, particularly in the proportionally smaller airways of children, can cause respiratory embarrassment and a bull-neck appearance. In both adults and children, a common cause of death is suffocation after aspiration of membrane [41].

\section{Clinical Manifestations}

Clinical manifestations of diphtheria usually begin two to seven days after infection. Clinical symptoms of diphtheria include fever of $38^{0} \mathrm{C}\left(100.4{ }^{0} \mathrm{~F}\right)$ or above, chills fatigue, bluish skin coloration(cyanosis), sore throat,horseness,cough,headache,difficultyswallowing, painful swallowing, difficultybreathing, rapid breathing, foul-smelling bloodstained nasal discharge and lymphadenopathy. Symptoms can also include cardiac arrhythmias, myocarditis, and cranial and peripheral nerve palsies $[43,44]$.Laryngeal diphtheria can lead to a characteristic swollen neck and throat, or "Bull-neck". The swollen throat is often accompanied by a serious respiratory condition, characterized by a brassy or "barking: cough,stridor,hoarseness, and difficulty breathing, and historically referred to variously as "Diphtheritic croup",[45], and "true croup"[46,47] or sometimes simply as "croup"[48].Diphtheria croup is extremely rare in countries where diphtheria vaccination is customary. As a result the term "croup" nowadays most often refers to an unrelated viral illness that produces similar but milder respiratory symptoms [49].

\section{Myocarditis}

Subtle evidence of myocarditis can be detected in as many as two third of patients, but $10 \%$ to $25 \%$ develop clinical cardiac dysfunction, with risk to an individual patient correlating directly with the extent and severity of local disease [50].Cardiac toxicity can be acute, with congestive failure and circulatory collapse, or more insidious, after 1 to 2 weeks of illness with progressive dyspnea, weakness, diminished heart sounds, cardiac dilation, and galloprhythm. Changes to electrocardiograph((ECG) pattern, particularly ST-T wave changes and first degree heart block, can progress to more severe forms of block, atrioventricular(AV) dissociation, and other arrhythmias, which carry an ominous prognosis. Patients with bundle-branch blocks and complex dissociation have a much higher incidence of death, and survivors may be left with permanent conduction defects [51].

\section{Neurological Toxicity}

Neurological toxicity is proportional to the severity of the primary infection: mild disease only produces neurotoxicity, but up to three fourth of the patients with severe disease can develop neuropathy. 
Within the first few days of disease, local paralysis of soft palate and posterior pharyngeal wall occurs commonly, manifested by regurgitation of swallowed fluids through the nose. Thereafter, cranial neuropathies causing oculomotor and ciliary paralysis are also common, and dysfunction of facial, pharyngeal, or laryngeal nerves, although rare, can contribute to the risk for aspiration. Peripheral neuritis develops later from 10days to 3 months after onset of disease in the throat [52].

\section{Miscellaneous diseases and Complications}

Skin infections due to Corynebacterium diphtheriae, more common in the tropics.Infections are characterized by chronic nonhealing ulcers, with dirty gray membrane and often associated with Staphylococcusaureus and group AStreptococci.More recently the significance of this infection in the United States has been by several outbreaks among alcoholic homeless men and impoverished groups such as Native Americans[53].The presentation is indolent and non-progressive and is only rarely associated with signs of intoxication. Nonetheless, these infections can induce high antitoxin levels and thus appear to act as natural immunization events [54].

Renal failure from direct toxin action or hypotension and pneumonia are common in severe cases. Rarely encephalitis and cerebral infarction have been described. Several excellent clinical descriptions of endemic and epidemic diphtheria in the United States indicate that both the frequency of various symptoms and the severity of disease are inversely proportional to the patient's immunization history [50].Roughly half of these reported cases were categorized as mild, often without membrane. Mortality rates from $3.5 \%$ to $12 \%$ and has not changed in the last 50 years. Rates are high in the very young and very old[55].

Endocarditismycoticaneurysms,osteomyelitis and septic arthritis have been described recently in cluster of drug addicts, alcoholics, Australian aboriginals and young adults[51],all caused by nontoxigenic C.diphtheriae.Ribotyping has indicated that these outbreaks have been caused by unique epidemic strains and both skin and throat colonization have been implicated as portals of entry. These illnesses have been characterized by aggressive course, a high proportion of bacteremia, endocarditis, arterial embolization, metastatic sites of infection (joints ,spleen, central nervous system) and high mortality. Why these nontoxigenic strains are so virulent remains a mystery [56].

\section{VI.Diagnosis and Treatment}

Isolation of Corynebacterium diphtheria from gram stain or throat culture from a clinical specimen [43] or histopathologic diagnosis of diphtheria by Albert stain.

Clinical criteria include:

(a) Upper respiratory tract illness with sore throat

(b) Low grade fever (above $39^{\circ} \mathrm{C}\left(102^{\circ} \mathrm{F}\right)$ is rare)

(c) An adherent, dense, gray pseudo- membrane covering the posterior aspect of the pharynx. In severe cases, it may extend to cover the entire tracheobronchial tree.

Diphtheria case classification:

- Probable: a clinically compatible case that is not laboratory-confirmed and is not epidemiologically linked to a laboratory-confirmed case

- Confirmed: a clinically compatible case that is either laboratory-confirmed or epidemiologically linked to a laboratory-confirmed case.

\section{Treatment}

The CDC recommends [57],either

- Metronidazole

- Erythromycin(orally or injection) for 14 days $(40 \mathrm{mg} / \mathrm{kg}$ per day with a maximum of $2 \mathrm{~g} / \mathrm{d}$ ),or

- Procaine penicillin G given intramuscularly for 14 days(300,000 U/d for patient weighing.>10kg and $600,000 \mathrm{U} / \mathrm{d}$ for those weighing for those weighing > 10kg).Patients with allergies to penicillin $\mathrm{G}$ or erythromycin can use rifampin or clindamycin,

\section{Prevention}

Diphtheria Immunization.Diphtheria can be prevented by immunization. The diphtheria vaccine was developed in 1923[58].It is on the World Health Organization's List of Essential Medicines, the most important needed in a basic health system[59].It use has resulted in a more than $90 \%$ decrease in number of cases globally between 1980 and 2000[60].Three initial doses are recommended after which it is about 95\% effective[59].It is effective for about 10 years at which time a booster dose is needed[59].Immunization may start at six weeks of age with further doses given every four weeks[60].The diphtheria vaccine is very safe, significant side effects are rare[60].The vaccine is safe in both pregnancy and among those who have poor immune function[1].The diphtheria vaccine is delivered in several combinations[6]. One includes tetanus toxoid(known as dT or DT 
vaccine) and other comes with the tetanus and pertussis vaccines,(DPT)[59].The World Health Organization has recommended its use since 1974, and about $84 \%$ of world population is vaccinated[62,60].

Recommendations from the Advisory Committee on Immunization Practices were up-dated in 2006 and 2008, published by CDC include:[63]

- For persons 11 years or more years old a single $0,5 \mathrm{ml}$, Tdap is followed four to eight weeks later by $0.5 \mathrm{ml}$ Td.with second dose of Td 6 to 12 months after the first.

- Booster immunization: persons 11 to 18 years old should receive one dose of Tdap and then receive the standard Td booster at 10 years later intervals.

- Those 19 to 64 years old should have their next booster as Tadp,to reduce carriage, clinical illness and transmission of pertussis[64].

\section{VIII.Conclusion}

Symptoms of diphtheria begin with respiratory tract infection, with production of white-gray pseudomembrane.In severe cases can cause respiratory embarrassment and a bull-neck appearance. Complications include myocarditis, neurological toxicity, endocarditis and renal failure. Early diagnosis and treatment have better outcome.

\section{References}

[1]. Atkinson W.Diphtheria Epidemiology and Prevention of Vaccine Preventable Diseases (12 ed.)Public Health Foundation.2012,pp.215-230.

[2]. Diphtheria vaccine(PDF).Wkly Epidemiology Rec.2006;81(3):24-32.

[3]. Mandell Douglas, and Bennett's Principles and Practice of Infectious Diseases (8 ed.).Elsevier HealthSciences.2014.p.2372.

[4]. Malacca Health Department, works to contain diphtheria after seven-year-old dies. Retrieved 2016-03-33.

[5]. GBD 2013 Mortality and Causes of Death,Collaborators(17 December 2014) Global,regional,and national age-sex specific all-cause and cause specific mortality for 240 causes of death,1990-2013:a systematic analysis for the Global Burden of Disease Study 2013.Lancet.385:117-71.

[6]. Centers for Disease Control. Diphtheria, tetanus, and pertussis recommendations for vaccine use and other preventive measures. Recommendations of Immunization Practices Advisory Committee (ACIP).MMWR Morb Mortal Wkly Rep.1991;40(RR-10):1-28.

[7]. LAVAL,Enrique.Wlgarotillo(difteria) enEspania(Siglos XVI y XVII)REvistaChilena de infectologia.2006;23.

[8]. Caufield E.A true history of the terrible epidemic vulgarly called The throat Distemper which occurred in His Majesty's New England colonies between 1735 and 1740. Yale J Biol Med.1939;11:219-272,277-335.

[9]. ON THE TREATMENT OF DIPHTHERIA IN 1735.Pediatrics(American Academy of Perdiatrics).1975;55(1):43.

[10]. FourgeaudVJ.Diphteritis: a concise historical and critical essay on the late epidemic pseud0-membranous sore throat ofCalifornia(1856-7),with a few remarks illustratingthediagnosis,pathology and treatment of the disease.California:Sacromento:J Anthony \& Co.1858.

[11]. KlebsE.UeberDiphtheria,Verh,Cong.inn Med.1883;2:139-154.

[12]. LoefflerF.UnterschugenijberdieBedeutung der Mikrooraganismen fur dieEntstehung der Diphtheria beim Menschen beider Taube und beim Kalbe, Mitt .klin. Gsndtsmte (Berlin)1884;2:421-499.

[13]. Gifford RR.The 0'Dwyer tube:Development and use in laryngeal diphtheria. ClinPediatr(Phil)1970;9(3):179-85.

[14]. Parish H.A history of immunization.E\&S.Livingstone.1965.p.120.

[15]. Behring E,KitasatoS.Ueber das Zustandekomen der Diphtheric-immuninitat and der Tetanus-immunitatbeiThieren(On the realization of diphtheria immunity and tetanus immunity among animals)Deutscemedizinsche Wpchenschrift.1890;16:1113-1114.

[16]. John MB.The Great Influenza:The story of the Deadliest Pandemic in History(New York:Penguin Books,c2004,2005).p.70.

[17]. Mulford HK Company(1903).Diphtheria Antitoxin. The Company.

[18]. Royer Frankin(1905).The Antitoxin Treatment of Diphtheria, with a Plea for Rational Dosage in Treatment and in Immunizing.

[19]. United States mortality rate from measles,scarletfever,typhoid,whoopingcough,and diphtheria from 19001965.HealthScetinel.com.Archieved from the original on 2008-05.Retrieved 2008-06-30.

[20]. Wilson Graham(2002).The Hazards of Immunization.Continuum International Publication,Limited,2002.p.20.

[21]. Histiory of Vaccines.Retrieved28 )ctober 2013.

[22]. HamischJP,TroncaE,NolanCM,etal.Diphtheriaamong alcoholic adults.A decade of experience in Seattle.AnnInt Med.1989;111(1):71-82.

[23]. ValdimirT.Contraindication to Vaccination in Russian Federation.Retrieved 28 June 2015.

[24]. CNN's Anderson Cooper talks with Sean Penn and Dr Sanjay Gupta about the threat of diphtheria in Haiti.CNN.com.Retrieved 2010-05-09.

[25]. Three kids die of diphtheria.TheHindu.Retrieved 2013-08-28.

[26]. Parents of diphtheria-striken boy feel"tricked by anti-vaccination groups". Retrieved 2015-06-05.

[27]. Meisje(3)overlijdtaandifterieinziekenhuis De Standaard.Retrieved 2016-03-18.

[28]. Daily Express,Sabah,July 24,2016.Six more confirmed cases of diphtheria in Negeri.

[29]. Freeman VJ.Studies on the virulence of bacteriophage-infected strains of Corynebacterium diphtheria.J Bacteriol.1951;61(6):67588.

[30]. Freeman VJ,MorseIU.Further observations on the change to virulence of bacteriophage-infected avirulent strains of Corynebacterium diphtheria.JBacteriol.1952;63(3):407-14.

[31]. Diptheria(http://www.textbookofbacteriology.net/diphtheria.html)from Today's 0nline Bacteriology(http://www.textbookofbacteriology.net/kt_toc.html),Kenneth Today 2009.Accessed 08 September 2010.

[32]. TABLE 1.Bacterial virulence properties altered by bacteriophages(http://iai.asm.org/cgi/content/full/79/8/3985/T1)from Patrick L Wagner,Matthew K Waldor.Bacteriophage Control of Bacterial Virulence.Infection and Immunity.2002;70(8):3985-3993.

[33]. Bell CE,EisenbergD.Crystal structure of diphtheria toxin bound to nicotinamide adenine dinucleotide.Biochemistry.1996;35(4):1137-49. 
[34]. Murphy R(1996).CotynebacteriumDiphtheriae:Diphtheria toxin production.In Baron S, et al.Medical Microbiology(4 ed.).Galveston,Texas:Univ.of Texas Medical Branch.

[35]. ChoeS,BenettMJ,FujiiG,etal. The crystal structure of diphtheria toxin.Nature. 1992;357(6375):216-22.

[36]. Bell CE,EisenbergD.Crystal structure of nucleotide-free diphtheria toxin.Biochemistry.1997;36(3):481-8

[37]. Bennett MJ,EisenbergD.Refined structure of monomeric diphtheria toxin at 2.3 A resolution.Protein Sci.1994;3(9):1464-75.

[38]. Bennett MJ,ChoeS,EisenbergD.Refined structure of dimeric diphtheria toxin at 2.0 A resolution.Protein Sci.1994;3(9):1444-63.

[39]. Victor JF.Studies on the Virulence of Bacteriophage-related Strains of Corynebacterium diphtheria. J Bacteriol.1951;61(6):675-88.

[40]. Freeman VJ,Morse IU; Morse. Further observations on the Change to Virulence of Bacteriphage-Infected Avirulent Strains of Corynebacterium diphtheriae.J Bacteriol.1953;63(3):407-14,

[41]. Macgregor RR.Corynebacteiumdiphtheria.In.Mandell,Douglas and InfectiousDiseases, $7^{\text {th }}$ ed.MandelGL,BennetteJE,Dolin R(editors), ,Churchill Livingstone Elsevier,2010.p.2687-2693.

[42]. PeppenhemierAM.The diphtheria bacillus and its toxin: A model System.JHyg(Camb)1984;93:397-440.

[43]. Diphtheria-Symptoms-NHS Choices.Retrieved 28 June 2015.

[44]. Pmldev.Udating PubMed Health.PubMedHealth.Retrieved 28 June 2015.

[45]. Loving Sterling.Someting concerning the diagnosis and treatment of false croup.JAMA:J Am Med Assoc.1895;XXV(14):567-73.

[46]. Cormack JR.Meaning of the Terms Diphtheria,Croup, and Faux Croup.Br Med J.1875;1(749):606.

[47]. Bennett JR.True and False Croup.Br Med J.1875;1(749):606-607.

[48]. Beard GM91875).Our home physician: A New and Popular Guide to the art of Preserving Health Treating Disease.New York:E.B.Treat.pp.560-564.

[49]. VanderpoolP.Recognizing croup and stridor in children.American Nurse today.2012;7(12)

[50]. Boyer NH,WeinsteinL.Diphtheriticmyocarditis.NEngl J Med.1948;239:913.

[51]. LedhetterMK,CannonAB,CoistaAF.The electrocardiogram in diphtheritic myocarditis.Am Heart J.1964;68:599-611.

[52]. Dobie RA,TobeyDN,Clinical features of diphtheria in the respiratory tract.JAMA.1979;242:2197-2201.

[53]. RommeyMG,RoscoeDL,BernardK,etal.Emergence of an invasive clone non-toxigenic Corynebacterium diphtheriae in the urban poor population of Vancouver,Canada.JClin Micro.2006;14:1625-29.

[54]. Bray JR,BurtEG,PotterEV,etal.Epidemic diphtheria and skin infection in Trinidad.J Infect Dis.1972;126:34-40.

[55]. RakhmanovaAG,LumioJ,GroundstormK,etal.Diphtheria outbreak in St.Petersburg:Clinical characteristics of1,860 adult patients.Scand J Infect Dis.1996;28:37-40.

[56]. Wilson APR.The return of Corynebcteriumdiphtheria:the rise of nontoxigenic strains.JHosp Infect.1993;30(Suppl):306-12.

[57]. The first version of this article was adopted from the CDC document"Diphtheria-1995 Case Definition" at http://www.cdc.gov./epo/dphsi/casedefi/diphtheria_current.html.Asa work of an agency of the U.S.Government without any other copyright notice it should be available as a public domain resource.

[58]. MaceraC.Introduction to Epidemiology:Distribution and Determinants ofDisease.Nelson Education.2012.p.251.

[59]. WHO Model List of Essential Medicines (PDF). World Health Organization.October 2013.Retrieved 22.April 2014.

[60]. Diphtheria vaccine(PDF).Wkly Epidemiology Rec 81(3):24-32.Jan 20,2006.

[61]. Centre for disease Control and Prevention.DiphtheriaVaccine.Department of Health and Human Services. Retrieved 8 November 2011.

[62]. Diphtheria.who.int.3 September 2014.Retrieved 27 March 2015.

[63]. Centers for Disease Control and Prevention: Preventing Tetanus,Diphtheria,and Pertussis Among Adults: Use of Tetanus Toxoid, Reduced Diphtheria Toxoid and Acellular Pertussis vaccine. Recommendations of the Advisory Committee on Immunization Practices and Recommendations of ACIP, supported by the Healthcare Infection Control Practices Advisory committee(HICPAC),for use of Tdap Among Health-care personnel.MMWRMorb Mortal Wkl Rep.2006;55:RR17.

[64]. Centers for Disease Control and Prevention. Health Information for International Travel 2008.Paul Arguin,PhyllisKozarsky,Christie Reed ed. Atlanta Ga: US Department of Health and Human Services;2008,142-45. 